\title{
REDE DE APOIO SOCIAL FAMILIAR E A PROMOÇÃO DO DESENVOLVIMENTO INFANTIL
} FAMILY'S SOCIAL SUPPORT NETWORK AND THE PROMOTION OF CHILD DEVELOPMENT RED DE APOYO SOCIAL FAMILIAR Y LA PROMOCIÓN DEL DESARROLLO INFANTIL

Recebido: 28/01/2015 Aprovado: 15/10/2015
Aline Oliveira Silveira ${ }^{1}$ Rafaella Costa Bernardes ${ }^{2}$ Monika Wernet ${ }^{3}$ Tatiana Barcelos Pontes ${ }^{4}$ Aline Araújo de Oliveira Silva ${ }^{5}$

Este estudo teve por objetivo descrever a percepção da família sobre os vínculos, a rede e o apoio social para cuidado e promoção do desenvolvimento da criança menor de cinco anos de idade. Para tanto, entrevistou-se sete famílias em vulnerabilidade social vinculadas ao sistema de saúde do Distrito Federal. Trata-se de estudo qualitativo, descritivo, sob o referencial da teoria de Rede Social Sistêmica. A análise das narrativas deu-se pelo método qualitativo de análise de conteúdo temática. Os resultados foram categorizados sob dois temas: "rede social familiar" e "vínculos e apoio social: percepção da família". A rede social utilizada é mínima, centrada na densidade das relações entre mãe, criança e avó, sob o sustento financeiro do pai. Há proximidade da moradia ao serviço de saúde, porém dissonâncias culturais nas relações com seus profissionais. Os profissionais de saúde precisam integrar em suas práticas o contexto microssocial e macrossocial das famílias enquanto determinantes das condições de saúde e de desenvolvimento infantil.

Descritores: Família; Desenvolvimento infantil; Apoio social; Vulnerabilidade social

The aim of this study was to describe the family perception about bonds, network and social support in terms of care and promotion of child development of children smaller than five years old. Seven families in social vulnerability, linked to the health system of Distrito Federal, Brazil, were interviewed. It is a qualitative descriptive study, structured on the Systemic Social Network Theory. Narrative analysis occurred by using the qualitative thematic content analysis. The results were categorized into two themes: "family social network" and "bonds and social support: family perception". The social network used is minimal, with density of relations between mother, child and grandmother, under the financial support from the father. There is proximity of housing to the health service, but cultural dissonance in relations with its employees. Health professionals need to integrate in their caring practice the micro social and the macro social context of families as determinants of health and child developmental conditions.

Descriptors: Family; Child development; Social support; Social vulnerability.

El objetivo de este estudio fue describir la percepción de la familia acerca de los vínculos, la red y el apoyo social para la atención y promoción del desarrollo de los niños menores de cinco años de edad. Siete familias que hacían parte del sistema de salud del Distrito Federal, Brasil, fueron entrevistadas. Esta es una investigación cualitativa, descriptiva, utilizando el referencial de la Teoría de Red Social Sistémica. Las narraciones fueron analizadas por el método cualitativo de análisis de contenido temático. Los resultados se agruparon en dos temas: "red social de la familia" y "lazos y apoyo social: la percepción de la familia". La red social utilizada es mínima, centrándose en la densidad de las relaciones entre la madre, el niño y su abuela, con apoyo financiero del padre. Hay proximidad de las viviendas a los servicios de salud, pero con disonancia cultural en las relaciones con sus profesionales. Los profesionales de salud deben integrar en su práctica de cuidado el contexto micro y macro social de la familia como determinantes de la salud y el desarrollo infantil.

Descriptores: Familia; Desarrollo infantil; Apoyo social; Vulnerabilidad social.

\footnotetext{
${ }^{1}$ Enfermeira. Mestre em Enfermagem Pediátrica. Doutora em Enfermagem. Professora Adjunta do Departamento de Enfermagem da Universidade de Brasília (UNB). alinesilveira@unb.br

2 Graduanda em Medicina pela UNB. rafaellacbernardes@gmail.com

${ }^{3}$ Enfermeira. Mestre em Enfermagem Pediátrica. Doutora em Enfermagem. Pós doutorado em Enfermagem. Professora Adjunta no Departamento de Enfermagem da Universidade Federal de São Carlos (UFSCar). mwernet@gmail.com

4Terapeuta Ocupacional. Mestre em Ciências da Saúde. Doutora em Saúde da Criança e do Adolescente. Pós doutorado pela Universidade de Toronto - Canadá. Professora Adjunta pela UNB. tatiana.pontes@gmail.com

${ }^{5}$ Graduanda em Psicologia pela UNB. aline.araujoos@gmail.com
} 


\section{INTRODUÇÃO}

A família, ambiente social primário da criança, é a principal fonte de estímulos ao seu desenvolvimento ${ }^{1}$, sendo as interações ali influentes do mesmo ${ }^{2}$. Neste contexto, o vínculo ${ }^{2}$ e a veiculação de afeto $^{1}$ entre criança e seu cuidador é considerado fator de proteção, enquanto que a desestruturação familiar, fator de risco ${ }^{2}$.

A unidade familiar, diante das demandas de cuidado da criança e com vistas a supri-las mobiliza recursos e estratégias ${ }^{1}$, entre os quais está a rede social. Esta é compreendida como o "conjunto de seres com quem se interage de maneira regular, com quem se conversa, com quem se trocam sinais, que corporiza, que tornam as pessoas reais"3. E, neste sentido, a rede social pessoal é a "soma de todas as relações que um indivíduo percebe como significativas ou define como diferenciadas da massa anônima da sociedade"2-4. Ela pode contribuir para o bem-estar e processos de enfrentamento e adaptação ${ }^{3}$.

A partir do entendimento de que as práticas de cuidado da família inscrevem-se em um quadro de rede de relações sociais ${ }^{3}$, os profissionais de saúde devem considera-la em seus projetos terapêuticos ${ }^{4,5}$. A promoção e estímulo do desenvolvimento infantil direcionam práticas na saúde ${ }^{2}$ e tem íntima articulação com o apoio profissional à família na identificação, acesso e uso de sua rede social. Tais aspectos ganham necessidade de atenção especial em contextos de vulnerabilidade social, onde é comum famílias chefiadas por mulheres e decorrentes, em grande parte de gravidez precoce e indesejada, instabilidade familiar e abandono ${ }^{6}$.

Desse modo, é relevante ampliar a compreensão da articulação entre a rede social e o cuidado familiar à criança em contextos de vulnerabilidade social, ou seja, onde se experiencia exclusão social com prejuízo aos direitos ${ }^{7}$. As relações estabelecidas, seja com amigos, familiares mais distantes, comunidade, ou aquelas com equipamentos sociais, como os serviços de saúde, tem papel fundamental para o desenvolvimento infantil $^{8}$ com recomendações de apreendê-las e mobilizálas com foco na atenção à saúde infantil ${ }^{9}$.

0 presente estudo toma como objeto o cuidado à criança em contexto de vulnerabilidade social sob a pergunta "como famílias em situação de vulnerabilidade social articulam a rede social no cuidado de suas crianças?". O objetivo foi de descrever a percepção da família sobre os vínculos, a rede e o apoio social para cuidado e promoção do desenvolvimento da criança menor de cinco anos de idade.

\section{MÉTODO}

Trata-se um estudo de abordagem qualitativa, por propor uma exploração que valorou o fenômeno como ele é vivenciado, com vistas ao entendimento dos sentidos e interpretações do mesmo nos termos de suas significações ${ }^{10}$.

Sete famílias em contexto de vulnerabilidade social que continham em sua unidade crianças menores de cinco anos de idade integraram o estudo. Outros critérios adotados foram: serem ambos os pais maiores de 18 anos de idade e estar à criança em acompanhamento de puericultura em serviço da Atenção Primária à Saúde (APS) pertencente à Regional de Saúde do Paranoá. Como critérios de exclusão adotou-se incapacidade de o membro da família gerar narrativa compreensível. Assim, participaram da entrevista sete mães, dois pais e uma avó materna.

A Regional de Saúde do Paranoá abrange o entorno leste de Brasília, Distrito Federal e integra três cidades: Paranoá, Itapuã e São Sebastião. Tal região tem relevante índice de vulnerabilidade social, a maioria de seus habitantes tem baixa renda, não concluíram o ensino fundamental ou são analfabetos $^{11}$. No que se refere à população infantil, a minoria das crianças $(4,9 \%)$ conta com creche ou pré-escola (uma na região), de forma que, quando os pais precisam se ausentar, cerca de $41 \%$ delas ficam em casa sob os cuidados de familiares, amigos, conhecidos ou sozinhas ${ }^{11}$.

0 acesso às famílias deu-se via unidades de saúde da APS, na ocasião de 
espera pela consulta de puericultura da criança. No primeiro contato foram fornecidas as informações sobre a pesquisa e realizado o convite para a participação na mesma. Frente ao interesse em participar agendava-se dia, horário e local de sua preferência. Todas as entrevistas foram realizadas em local privativo na própria unidade de saúde, respeitando-se a escolha da família.

Todas as recomendações éticas na pesquisa com seres humanos foram seguidas. A pesquisa iniciou-se após a aprovação do Comitê de Ética em Pesquisa da Secretaria de Estado do Distrito Federal - FEPECS/SES/DF, sob o protocolo de número 153.841, e a participação dos sujeitos foi oficializada por meio da leitura e assinatura do Termo de Consentimento Livre Esclarecido (TCLE).

A coleta de dados foi realizada no ano de 2014, utilizando-se a estratégia de entrevista, desenvolvida em duas etapas. No primeiro momento houve a construção do genograma e do Mapa Mínimo de Relações (MMR) ${ }^{3}$. 0 genograma é um instrumento utilizado para a avaliação da estrutura interna da família ${ }^{12}$, enquanto que o MMR mapeia a rede social por meio da exploração de relações sociais: amizade; família; relações de trabalho e estudo; e relações comunitárias: sistema de saúde e agências sociais. Nesta exploração, o MMR adota três graus de proximidade: relações com maior grau de compromisso, relações de compromisso intermediário e relações ocasionais ${ }^{3}$. Estas, por sua vez, são categorizadas quanto às seguintes características estruturais: tamanho, densidade, composição, dispersão, homogeneidade/heterogeneidade e funções da rede $^{3}$.

Após a primeira etapa, a entrevista foi desenvolvida a partir das questões: "olhando para o seu genograma quem vocês consideram que são as pessoas que mais contribuem para o cuidado e desenvolvimento de sua criança? Como contribui?"; "Dentre os recursos identificados por vocês, qual vocês consideram que ajuda mais no cuidado com a criança? Por quê?"; "Vocês sentem falta de algum serviço ou recurso para cuidar e promover o desenvolvimento saudável de seu filho?". Aspectos como dificuldades e facilidades, presença ou ausência de recursos e sentimentos em relação ao cuidado e desenvolvimento da criança foram explorados ao longo da entrevista.

Todas as entrevistas foram gravadas em áudio, transcritas na integra e, posteriormente, analisadas a partir das etapas preconizadas pelo método de análise qualitativa de conteúdo ${ }^{10}$, a luz do Modelo de Rede Social Sistêmica ${ }^{3}$.

A condução da análise envolveu os seguintes passos sistemáticos: codificação dos dados; categorização dos dados e integração dos mesmos em núcleos temáticos ${ }^{10}$. Houve leitura e releitura das entrevistas com a identificação das concepções da família acerca dos vínculos e do apoio social e sua influência no cuidado e promoção do desenvolvimento saudável da criança. Tais elementos foram analisados e integrados considerando-se: as características estruturais da família e da sua rede social e as relações estabelecidas pela família com os sistemas de apoio social.

\section{RESULTADOS}

As famílias demonstraram como características de sua estrutura interna: formação nuclear, composição de adultos jovens com idade materna entre 18 a 39 anos e paterna de 18 a 37 anos e baixa escolaridade, variando de ensino fundamental incompleto a ensino médio incompleto. Em três famílias coabitavam na mesma residência membros da família extensiva: avós maternos, tio materno e nora. Exceto uma família que tinha filho adolescente, as demais estavam no estágio de filhos pequenos, com crianças de um mês e 10 dias até quatro anos de idade. As mães eram as cuidadoras principais da criança, de forma que apenas uma delas era integrante do mercado de trabalho.

Os resultados foram categorizados em dois temas: "rede social familiar" e "vínculos e apoio social: percepção da família".

\section{- A rede social familiar}

A Figura 1 traz o MMR revelado pelo estudo.

Quanto ao tamanho, dado relativo ao número de pessoas ou instituições sociais que compõe a rede, identifica-se a predominância de uma rede mínima ou de pequeno porte, 
com variação de quatro a 10 pessoas ou instituições sociais apontadas como significativas para o cuidado da criança.

Em relação à densidade, ou seja, o grau de conexão entre os membros e a efetividade da rede, observou-se que ao analisar-se a rede como um todo, identifica-se uma baixa densidade, enquanto que, ao focalizarem-se os subsistemas familiares identifica-se uma densidade mais elevada na relação mãe-filho, na relação mãe-avó e na relação avó-neto.
Na composição ou distribuição das pessoas que compõe a rede observa-se uma centralidade na família, representada pelos familiares diretos com os quais a criança tem uma relação cotidiana (mãe, pai, irmãos e avós) e por membros da família extensiva que têm uma relação constante, porém com menor proximidade e grau de compromisso com a criança (tios, tias, padrinhos e madrinhas).

Figura 1: Mapa Mínimo de Relações (MMR) demonstrativo da Rede Social de Apoio Familiar para o cuidado e promoção do desenvolvimento da criança nos primeiros cinco anos de vida das famílias entrevistadas no estudo, Distrito Federal, 2014.

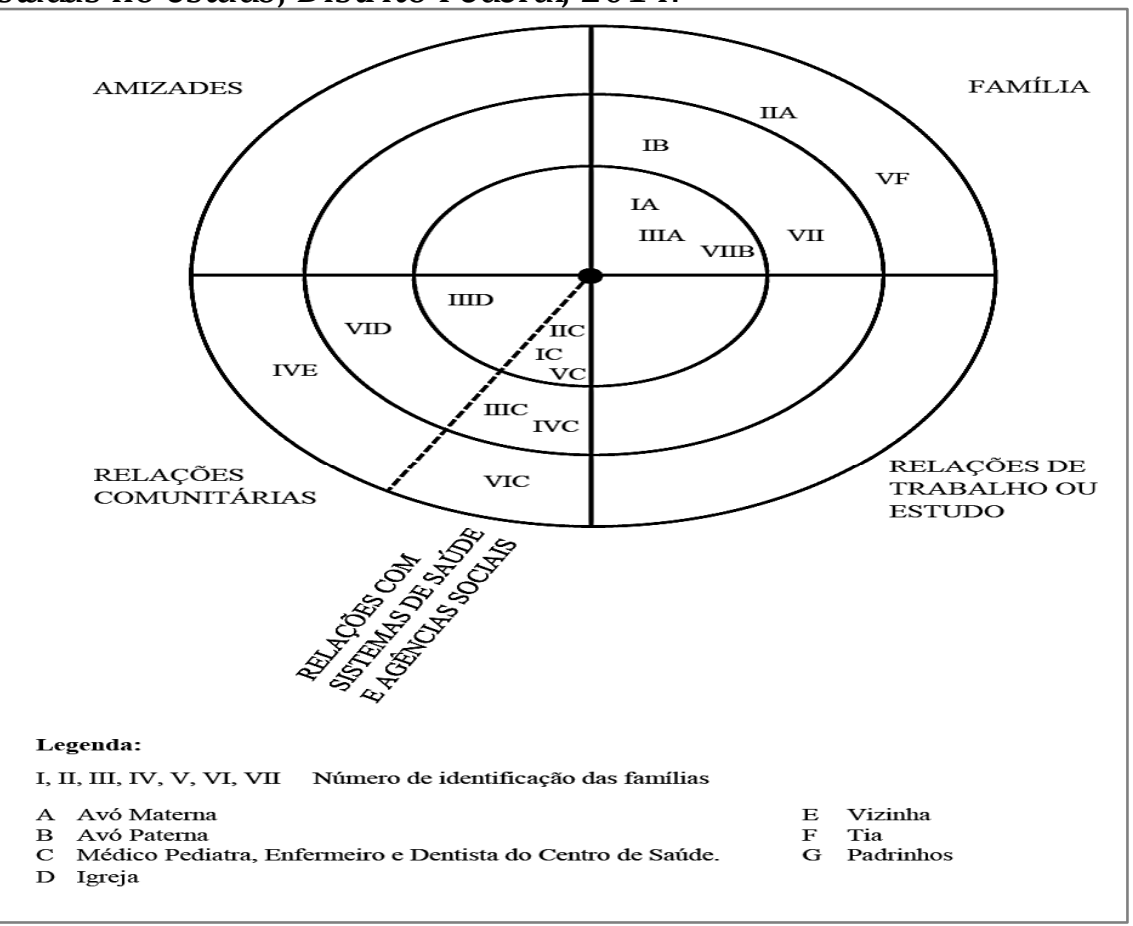

No âmbito das relações comunitárias há um destaque para os sistemas de saúde (profissionais da atenção primária) e, em menor proporção, entidades religiosas, vizinhos e amigos, em contraste com a inexistência de relações apontadas como significativas com sistemas de educação (creches ou pré-escola), agências ou organizações sociais.

Nas relações de estudo e de trabalho, evidencia-se $o$ não reconhecimento de pessoas significativas que atuam diretamente como apoio na promoção da saúde e do desenvolvimento da criança. Entretanto, os recursos advindos do trabalho permitem ao pai desempenhar a função de sustentar financeiramente a família.

No que se refere à dispersão das pessoas significativas que compõe a rede, a distância geográfica foi apontada como barreira. Destaca-se a migração e a limitação de recursos financeiros como eventos potencializadores da distância e da fragmentação da rede familiar. Assim, as pessoas que tem uma relação de maior proximidade são aquelas que residem perto. A proximidade entre o serviço de saúde e o local de moradia da família foi apontada como o principal fator facilitador do acesso e do vínculo para acompanhamento do crescimento e desenvolvimento da criança. 
A rede social delineada pela família tem como característica predominante à homogeneidade demográfica e sociocultural: baixa escolaridade dos pais e membros significativos que cuidam da criança; baixo nível econômico; a multiplicidade de filhos entre os componentes da rede e composição predominante de adultos jovens com pequena representação de pessoas mais velhas ou idosas. Os profissionais de saúde, enquanto subgrupo com características sociais e culturais distintas intersectam a rede familiar, tornando-a heterogênea, e atuam como intermediadores de práticas sociais voltadas ao cuidado da criança nos primeiros anos de vida.

Dentre as funções predominantes da rede familiar, destacam-se: apoio emocional, apoio espiritual; guia cognitivo; regulação social e a ajuda material e de serviços. 0 apoio emocional e instrumental para o cuidado da criança são funções predominantes da rede familiar. A regulação social e a função de guia cognitivo são predominantes na relação com os profissionais de saúde. As pessoas ligadas às entidades religiosas também exercem a função de guias cognitivos, transmitindo apoio espiritual e crenças, que moldam determinados comportamentos, práticas educativas e de cuidado de saúde. 0 sistema de saúde, representado pelos profissionais que atuam na APS, tem como função predominante a ajuda material e de serviços, como as consultas de crescimento e desenvolvimento; a vacinação; as consultas de odontologia, e na situação de doença da criança: o pronto atendimento e o acesso a exames, medicamentos e tratamentos.

- Vínculos e apoio social: percepção da família

0 cuidado da criança nos primeiros anos de vida altera a dinâmica, a diversidade e a abrangência da rede social familiar. 0 apoio social e o fortalecimento da família são compreendidos como resultados das relações estabelecidas em quatro dimensões, a partir das quais este tema é apresentado: relações familiares; relações de trabalho; relações comunitárias e relações com serviços de saúde.

* Relações Familiares
Conjunto de vínculos estabelecidos entre os indivíduos que compõe o núcleo familiar imediato da criança e entre esses, a rede familiar mais ampla ou família extensiva.

A criança pequena é concebida como vulnerável e dependente o que determina que ela seja foco de atenção da família. Esta, por sua vez, significa-se como o primeiro e principal espaço relacional e favorecedor da saúde e do desenvolvimento da criança. Nesse contexto a mãe exerce a função de suprir as necessidades da criança, através da sua presença constante; da alimentação; dos cuidados cotidianos de higiene e conforto; do estímulo oferecido por meio de diálogos, contato e brincadeiras; e do manejo de intercorrências de saúde.

0 cuidado da criança como uma função predominante do vínculo materno apoia-se nas concepções socialmente construídas de ser o cuidado a responsabilidade do gênero feminino e de poder a amamentação ser praticada exclusivamente pela mãe. Estes atributos restringem a divisão do cuidado da criança com outras pessoas.

A mãe é o principal vínculo e apoio social para a criança crescer e se desenvolver de forma saudável. É assim que a família define a função materna e, por sua vez, é assim que a mãe define seu próprio papel e funções predominantes dentro da família. Com base nisso, os demais membros da família assumem uma posição intermediária ou periférica na rede de cuidados e promoção do desenvolvimento da criança, com contatos menos frequentes, relacionamentos e vínculos de menor intensidade e menor compromisso com o bem-estar da criança. Nesse contexto relacional estão presentes o pai, os avós e os padrinhos como pessoas importantes na vida da criança e que exercem influências diretas ou indiretas no seu desenvolvimento.

0 pai tem como função predominante prover o sustento econômico. 0 trabalho reduz seu tempo de interação com a criança, no entanto, quando se faz presente, assume, com grau de compromisso variado, a responsabilidade, dividindo as demandas de cuidado com a mulher. A forma como o pai assume seu papel na relação com os filhos e com a mulher depende de seus valores e de 
habilidades para organizar as atividades da vida diária no sentido de encontrar tempo e disponibilidade emocional para interagir com a criança, como apontado nas falas:

Eu não costumo deixar ele (filho) com ninguém, nem com minha mãe, porque ele (filho) é muito novinho, mama no peito ainda, mas quando meu esposo está em casa é ele que me ajuda, a cuidar, a trocar, esse tipo de coisa (mãe, família 6)

A mãe é quem cuida dele (neto), com certeza, ela é a mãe, tem que cuidar... eu também, segunda né, mãe (avó materna, família, 3)

Eu converso, estimulo ele (filho)... as madrinhas também a minha amiga vê ele direto porque mora perto, a minha irmã umas duas vezes por mês porque mora longe... elas vem, brincam com ele, ajudam a cuidar, dão muito presente... a minha sogra também. (mãe, família 7)

As avós, maternas e paternas, são as principais fontes de apoio. Entretanto são acessadas em momentos, identificados pela mãe, como de necessidade extrema. São apontadas como pessoas importantes para a criança, no entanto, o contato e o apoio estão condicionados à urgência da situação, a disponibilidade de tempo e à proximidade geográfica.

A dependência do apoio informal para o cuidado da criança é questionada pela mãe, pois avalia que as condições e os recursos das mulheres que compõe a rede (tias, avós, madrinhas, amigas, vizinhas) são por vezes extremamente escassos. Tal constatação a impede o pedido de ajuda na família extensiva e a busca de alternativas formais, como creches e pré-escolas, que se apresentam como possibilidades. Contudo, a ausência de confiança na qualidade do cuidado ofertado nesses ambientes e a dificuldade de acesso são desafios nessa trajetória e na tentativa de ampliar a rede de apoio, como observado na seguinte descrição:

A minha mãe ajuda, mas é muito raro, muito difícil, se precisar muito ela (filha) fica com a minha mãe, mas só quando não dá para levar ela (filha) junto, porque é muito difícil, porque ela (avó) não mora perto de mim, ela não mora aqui no Paranoá (mãe, família 2)

0 cuidado da criança é um processo social, construído e reconstruído conforme as demandas identificadas pela mãe. Exige da mãe habilidades, que perpassam os domínios cognitivo, emocional e instrumental, bem como recursos materiais e financeiros. Dentre as principais dificuldades percebidas pelas mães estão: o medo de dar banho nos primeiros dias de vida; o manejo das cólicas; a ausência de descanso noturno; a sobrecarga com as atividades domésticas; a vigilância e prevenção de acidentes, o manejo de doenças e questões financeiras para o cuidado. Neste contexto, sentimentos de solidão e desespero são relatados pela mãe, bem como insegurança na tomada de decisão sobre a melhor maneira de cuidar da criança, como nas falas:

A minha mãe só banha ela, porque eu não banho não. Eu tenho medo. Aí minha mãe vem em casa banhar ela... mas o mais difícil é que ela sente muita cólica e aí eu fico desesperada pensando no que eu vou fazer... ela sente muita cólica e não dorme de noite e... sozinha eu fico acordada para cuidar dela (mãe, família 1)

o mais difícil assim... é o cuidado que tem que ter toda hora para não cair, não se machucar, e quando fica doente...(mãe, família 4)

É difícil assim, a gente paga aluguel e ele (filho) não pode mamar no peito, dai tem que comprar o leite, e o leite é caro (mãe, família 7)

* Relações de Trabalho

As relações de trabalho envolvem vinculação com pessoas e instituições capazes de gerar apoio formal ou informal para a família cuidar e prover o desenvolvimento da criança. A importância do vínculo com o trabalho, para essas famílias, centra-se nesse como meio de adquirir os recursos para as necessidades essenciais de moradia, conforto, vestimenta, alimentação adequada e transporte. As pessoas das relações de trabalho não são identificadas como integrantes da rede social da família.

No contexto do trabalho, a principal mudança se dá no vínculo da mulher. Ao tornar-se mãe e assumir para si a reponsabilidade pelo cuidado da criança, as mulheres desse estudo tomaram a decisão de romper seus vínculos com o trabalho para dedicarem-se integralmente ao cuidado da criança. Entretanto, a mulher passa a viver um conflito entre os seus deveres de mãe e a necessidade financeira da família. Apesar de a criança beneficiar-se da sua presença os recursos financeiros se tornam mais escassos, podendo acarretar dificuldades.

O homem, pai, por sua vez, assume para si a responsabilidade pelo sustento financeiro da família e fortalece seu vínculo com o trabalho. Quando as necessidades excedem os recursos a mulher sente-se na 
obrigatoriedade de ajudar financeiramente, quando recorre ao trabalho informal. Também se visualiza como alternativa partilhar a função de sustento com os padrinhos da criança.

A mulher planeja voltar a trabalhar e estudar, pois sabe da importância desse apoio para a saúde e para a garantia de melhores condições de vida para a criança. A meta para o retorno ao trabalho pauta-se: na idade do desmame da criança; na idade que a criança tiver menor vulnerabilidade à doença e maior independência e na segurança de continuidade do cuidado. Entretanto, a ausência de recursos comunitários, condições financeiras e de apoio formal ou informal para o cuidado dos filhos pequenos faz com que a mulher desista da continuidade do trabalho ou de suas perspectivas de estudo, rompendo definitivamente o vínculo e perpetuando uma condição de baixa escolaridade e renda na família, como colocado na falas:

Eu sai do meu serviço né, porque não tinha ninguém que cuidasse dele, então eu sinto falta do meu trabalho, mas eu sai por necessidade própria mesmo para cuidar dele (filho), ... agora só meu marido que está trabalhando (mãe, família 4)

Para melhorar o cuidado eu tenho que trabalhar também. ... quando ela fizer seis meses eu vou trabalhar né? (mãe, família 1)

* Relações Comunitárias

Englobam o conjunto de interações e vinculações que são estabelecidas pela família em sua comunidade com pessoas e instituições sociais. A comunidade exerce um papel estruturante para as relações familiares e no processo de desenvolvimento infantil. Tem o potencial de prover novas dimensões de interação e ampliar o espaço relacional da família, a depender da história, do tempo e da forma como a família interage e se integra a sua comunidade.

As relações comunitárias, bem como os vínculos e apoio social, articulados a esse contexto, centram-se naquelas estabelecidas com os serviços de saúde e com a igreja. As relações com vizinhos e amigos são restritas e são raros aqueles que atuam como apoio.

As relações com os sistemas de educação são inexistentes. A família atribui a isso a ausência de acesso (não existência de vaga) e à ausência de confiança nas instituições presentes na comunidade. No que se refere ao setor privado, a condição financeira é impeditiva do acesso.

As atividades de lazer são restritas ao domicílio e visitas a parentes que residem próximos. Revela-se com isso a dificuldade de a família encontrar recursos úteis em seu meio social, vistas nas falas a seguir:

A gente (pais e filhos) costuma sempre ir a igreja, três dias da semana, e na casa da minha mãe, só... (mãe, família 6)

A creche né... falta... eu estou querendo arrumar escolinha para ela, não tem vaga... ... já vai fazer 5 anos né... (mãe, família 5)

O vínculo com sistemas de saúde, apesar de presente e considerado importante, é visto como tênue. A dificuldade de acesso às consultas, o tempo de espera, a escassez de profissionais, a dificuldade de identificá-los e sua abordagem pouco acolhedora e respeitosa são aspectos apontados como barreiras para a vinculação. Por outro lado, a proximidade geográfica entre o serviço de saúde e o domicílio facilita o acesso e a abordagem acolhedora de alguns profissionais favorece $o$ vínculo.

O diálogo, entre o profissional e a família, é identificado como importante recurso para o fortalecimento do vínculo, sendo valorados e percebidos como fonte de apoio social aqueles profissionais atenciosos, que permitem à família expor seus questionamentos; que esclarecem dúvidas e ensinam os cuidados com a criança, como apontado:

Eu não tenho do que reclamar, os médicos são bons, atenciosos, perguntam como é que tá... ajudam muito... quando ela estava com um mês, ela perdeu peso, ela veio perdendo muito peso porque eu não estava sabendo amamentar direito, eu achava que ela estava mamando, e ela não estava sugando, aí ela ficou com um quilo $e$ pouco, ai me encaminharam para o hospital, onde só é colhido leite materno, aí lá tem um médico muito bom que me indicou, me ensinou direitinho, ai ela foi pegando peso, agora ela esta normal, mas se não fosse ele (médico) ela estava internada. Me levaram para o banco de leite, ai foi que me orientaram, o médico de lá muito bom, ele me ligava em casa para saber como é que ela estava, com aquela preocupação que eu nunca tinha visto de médico, eu até me surpreendi (mãe, família 2)

Por outro lado, o profissional não é visto como apoio quando adota uma postura hierárquica e possesiva: de ausência de abertura para perguntas e indisponibilidade para a escuta; de medicalização da criança

REFACS (online) 2016; 4(1):6-16. 
sem buscar compreender seu problema; e de negligência frente à situação da criança e da família. Essa abordagem faz com que a família se cale, frente ao receio de ser mal tratada e a vergonha decorrente disso, guardando para si suas dúvidas, preocupações e necessidades. A negligência do profissional, muitas vezes, leva a família a desvincular-se definitivamente do serviço público de saúde e buscar alternativas no setor privado, mesmo com recursos financeiros escassos. Especialmente nas situações de doença da criança, as famílias percebem-se sozinhas, como observado nas descrições:

Eu não gostei... levei ele (filho) no médico e o médico passou remédio, mas não chegou a tocar nele, não examinou ele em nada, perguntou o que ele tinha, eu falei, aí pronto, colocou lá no papelzinho e pronto... não dão abertura, só fazem as perguntas deles, pergunta, você responde e manda embora (mãe, família 5)

A gente não pode perguntar nada porque ela (profissional) vem com grosseria para a gente, aí fica muito difícil porque as vezes a gente tem dúvida e a gente nunca pergunta... quando ele teve com pneumonia, eu pensei que eles (profissionais) iam me ajudar mais, mas não ajudaram, simplesmente falaram que ele não tinha nada e ai eu levei no hospital particular e me falaram que estava com começo de pneumonia, ai eu tive que me virar sozinha em casa, comprar remédio, tive que me virar sozinha, eu e meu marido (mãe, família 4).

As relações estabelecidas com o sistema de saúde, ainda que problemáticas e fragmentadas, foram identificadas como o principal, por vezes único, apoio comunitário para o cuidado e promoção do desenvolvimento saudável da criança. Entretanto, a qualidade e o tipo de apoio que encontram nesse sistema social são variáveis. Quando identificados como fonte de apoio, o conteúdo centra-se nas informações e explicações que proporcionaram a aquisição de conhecimentos para cuidar melhor da criança, sendo citado o correto manejo da amamentação e da alimentação infantil; a identificação e tratamento de infecções intestinais; o manejo da febre; a oferta de serviços de vacinação, de consulta de crescimento e desenvolvimento e de odontologia para a criança.

As consultas de crescimento e desenvolvimento são identificadas como um serviço importante para a certificação do bem-estar da criança. 0 bem-estar da criança, muitas vezes, reduz-se à compreensão do peso e estatura adequados. Esses indicadores antropométricos são parâmetros utilizados pela família, e pelo profissional de saúde, para avaliar a qualidade do cuidado ofertado à criança no domicilio, revelando uma percepção limitada de desenvolvimento infantil.

\section{DISCUSSÃO}

A rede social familiar tem influência na saúde, na constituição e no desenvolvimento da criança. 0 mapeamento da rede social e a percepção da família acerca dos vínculos que estabelece e das dimensões de apoio revelaram áreas de fragilidade e de ausência de recursos fundamentais para a potencialização das ações de saúde numa perspectiva de promoção do desenvolvimento infantil.

Destaca-se a fragilidade estrutural da rede social no que concerne a pequena quantidade de pessoas identificadas como fonte de apoio; ao grau de conexão: alto nível de densidade entre a mãe-criança e baixo entre os demais membros da rede; a dificuldade de acesso às pessoas, serviços e recursos sociais; e as características socioculturais predominantes: baixa escolaridade, condições de trabalho e renda.

As redes de pequeno porte ou mínimas são menos efetivas em situações de excesso de demandas ou tensão de longa duração, podendo gerar sobrecarga ${ }^{3}$. As redes sociais modificam-se ao longo do ciclo de vida ${ }^{13}$ e dentre os eventos normativos a transição para a paternidade ${ }^{13}$, a migração ${ }^{3,14}$ e as mudanças nas relações de trabalho, como a saída da mãe, podem reduzir o tamanho da rede e a disponibilidade de apoio social, fatos encontrados neste estudo.

Sabe-se que as famílias com filhos pequenos enfrentam múltiplas demandas e desafios cotidianos para conciliar tarefas financeiras e domésticas, e desempenhar suas funções básicas de proteção, alimentação, conforto e a socialização ${ }^{15}$. Os efeitos das transições podem ser mais significativos quando as dificuldades e instabilidades já se fazem presentes na vida familiar em decorrência de sua baixa condição sociocultural, privação financeira e ausência 
de recursos para lidar com estressores adicionais 6,16 .

Torna-se importante considerar a família como o ambiente primário e os pais como núcleo social de promoção do desenvolvimento da criança. Na medida em que a instabilidade familiar influencia o acesso a recursos e seu bem-estar psicoemocional esse processo afeta a qualidade do cuidado e, consequentemente, o bem-estar da criança ${ }^{16}$. Pode-se inferir que a ausência de uma rede de apoio sensível às necessidades da família nessa fase do seu ciclo de vida pode potencializar os estressores, gerar sobrecarga e comprometer a variedade e qualidade dos vínculos, do cuidado parental, das experiências interacionais e dos estímulos ao desenvolvimento da criança.

No que se refere à coesão, o alto nível de densidade conduz a relacionamentos rígidos, enquanto que, um baixo nível de densidade também reduz a efetividade da rede pela ausência de preocupação uns com os outros $^{3}$. Essa constatação indica que as necessidades familiares ficam parcialmente negligenciadas, o que pode implicar em fator de risco ${ }^{3}$. Dado encontrado neste estudo.

A dispersão ou distância geográfica entre os membros da rede social, afeta a facilidade de acesso e a sensibilidade da rede às variações de necessidade de apoio do indivíduo ${ }^{3}$. Pode-se afirmar que as características socioculturais, em especial a limitação de recursos financeiros, potencializam a distância, restringem os contatos e o acesso, criando e mantendo uma rede social adstrita à região de domicílio das famílias. A homogeneidade da rede tem vantagens no que se refere à facilidade de identificação sociocultural entre os indivíduos, entretanto a capacidade de prover apoio fica limitada ${ }^{12}$. Uma rede heterogênea facilita a ativação e utilização de sistemas de apoio, ampliando o conteúdo e as oportunidades de interações, as experiências e os aprendizados ${ }^{3}$.

Dentre as dimensões de apoio exercidas pela rede social familiar identifica-se o apoio instrumental, apoio financeiro ou material e de serviços de saúde e o apoio cognitivo exercido tanto pelos familiares mais próximos da criança como pelos profissionais de saúde. Há uma forte relação entre o apoio instrumental percebido e acessado pela mãe e a saúde da criança ${ }^{17}$. Mães que possuem apoio financeiro, disponibilidade para o cuidado da criança e apoio no cuidado da casa experienciam maior satisfação social e bemestar, resultando em maiores benefícios para a saúde da criança ${ }^{17}$. Por outro lado, o baixo apoio social materno pode contribuir para a transmissão intergeracional de riscos e dificuldades sociais ${ }^{6,17}$. A diminuição das necessidades materiais aumenta o senso de controle pessoal e reduz a negligência parental ${ }^{18}$.

Destaca-se a ausência recursos para atividades de lazer e de vínculo com centros de educação como importantes determinantes para a saúde e desenvolvimento da criança. Muitas crianças menores de cinco anos não atingem seu potencial de desenvolvimento principalmente por causa da pobreza, de deficiências nutricionais e de inadequadas oportunidades de aprendizado e estimulação ${ }^{19}$. A qualidade do ambiente de educação infantil e a habilidade para acessar e beneficiar-se de programas de intervenção são apontados como mecanismos de proteção intimamente relacionados à educação materna ${ }^{19}$. Contudo, a disponibilidade de equipamentos sociais voltados à educação mostrou-se incipiente em número, bem como em qualidade de vínculo na população aqui estudada.

Os resultados validam elementos da rede social de apoio familiar evidenciados em estudos anteriores, especialmente no que concerne a presença de dois tipos de rede - as redes de apoio formais, representada pelas relações com profissionais, e as redes de apoio informais, representada pelas relações pessoais constituídas na família e na comunidade $^{5}$. Na rede de apoio informal a família extensiva, em especial as avós e, com menor grau de compromisso outros membros do gênero feminino, tem participação no cuidado e na promoção do desenvolvimento infantil $^{5}$. Nas redes informais, a coesão e o controle social, quando presentes na comunidade, geram um maior apoio social, que é relacionado a estilos de parentalidade mais efetivos, especialmente no que se refere 
à qualidade da comunicação pais-filhos e a vigilância ${ }^{20}$.

\section{CONCLUSÃO}

0 estudo traz uma compreensão sobre a estrutura e a dinâmica da rede e do apoio social familiar no cuidado e promoção do desenvolvimento da criança em contexto de vulnerabilidade social. Tal compreensão permitiu a identificação das dimensões de apoio social e, por consequência, áreas de força e de fragilidade com implicações no funcionamento familiar e, consequentemente no desenvolvimento infantil.

0 profissional de saúde deve considerar $\mathrm{o}$ contexto microssocial $\mathrm{e}$ macrossocial das famílias enquanto determinantes das condições de vida, de saúde e de desenvolvimento infantil. Para tanto, torna-se necessário mudanças nos paradigmas e práticas de cuidar com: 1) a adoção dos conceitos de rede social e de apoio social; 2) incorporação de instrumentos que explorem o ambiente social, como o genograma e MMR; 3) o reconhecimento do impacto da rede social no desenvolvimento infantil, particularmente em situação de vulnerabilidade social e migrações; e, 4) intervenções focalizadas na construção de redes efetivas, que permitam às famílias potencializarem seus recursos e acessarem o apoio que necessitam. Esse olhar ampliado contribui para o desenvolvimento infantil e tem potencial de empoderar famílias em vulnerabilidade social.

Este estudo, ao explorar a rede social no cuidado à criança, demonstrou a relevância de atribuir valor a tal elemento nas práticas de atenção à saúde da criança. Ressalta-se que outras pesquisas devem buscar avançar nas questões ligadas à rede social e o cuidado familiar à criança, em busca de compreensão do como a rede social pode ser abordada e explorada no cuidado em saúde voltado à promoção do desenvolvimento infantil.

Além disto, equipamentos vinculados à educação revelaram-se como fragilidade no cenário estudado, sem exploração mais densa da relação Saúde, Educação e promoção do desenvolvimento infantil, fato que precisa ser explorado em outros estudos. Os anos de estudo materno têm correlação direta com ambientes promotores ao desenvolvimento infantil e, neste sentido, as relações com os equipamentos de educação revelaram-se frágeis no estudo e merecem futuras explorações.

Dentre as limitações do estudo, obteve-se uma compreensão transversal da dinâmica da rede social familiar, a partir de uma perspectiva metodológica qualitativa interpretativa circunscrita ao contexto de uma região do Centro-Oeste brasileiro. Assim, sugerem-se novas pesquisas sob outros enfoques metodológicos e/ou com populações de diferentes regiões brasileiras.

\section{REFERENCIAS}

1. Oliveira DKS, Nascimento DDG, Marcolino FF. Perceptions of family caregivers and professionals in the family health strategy related to the care and neuropsychomotor development of children. J Hum Growth Dev. [Internet]. 2012 [citado em 28 jan 2014]; 22(2):142-50. Disponível em: http://www.revistas.usp.br/jhgd/article/vie $\mathrm{w} / 44943 / 48565$.

2. Falbo BCP, Andrade RD, Furtado MCC, Mello DF. Estímulo ao desenvolvimento infantil: produção do conhecimento em enfermagem. Rev Bras Enferm. [Internet]. 2012 [citado em 28 jan 2014]; 65(1):148-54. Disponível

em: http://www.scielo.br/pdf/reben/v65n1/22. pdf.

3. Sluski CE. A rede social na prática sistêmica - alternativas terapêuticas. São Paulo: Casa do Psicólogo; 1997.

4. Vanderlinde LF, Borba GA, Vieira ML. Importância da rede social de apoio para mães de crianças na primeira infância. Rev Ciênc Hum. [Internet]. 2009 [citado em 5 fev 2014]; 43(2):429-43. Disponível em: https://periodicos.ufsc.br/index.php/revistac fh/article/view/2178-

4582.2009v43n2p429/12486.

5. Alexandre AMC, Labrocini LM, Maftum M.A, Mazza VA. Mapa da rede social de apoio às famílias para a promoção do desenvolvimento infantil. Rev Esc Enferm USP. [Internet]. 2012 [citado em 5 fev 2014]; 46(2):272-9. 
Disponível

em:

http://www.scielo.br/pdf/reeusp/v46n2/a02 v46n2.pdf.

6. Pinto RMF, Micheletti FABO, Bernardes LM, Fernandes JMPA, Monteiro GV, Silva MLN. Condição feminina de mulheres chefes de família em situação de vulnerabilidade social. Serv Soc Soc. 2011; 105:167-79.

7. Gomes CVA, Santos BVBS, Santos FL, Santos GMO, Andrade MH, Neves AF et al. Políticas públicas e vulnerabilidade social: uma reflexão a partir de experiência de estágio. Rev Ciênc Ext. 2015; 11(1):116-30.

8. Furtado MCC, Silva LCT, Mello DF, Lima RAG, Petri MD, Rosário MM. A integralidade da assistência à criança na percepção do aluno de graduação em enfermagem. Rev Bras Enferm. [Internet]. 2012 [citado em 5 fev 2014]; 65(1):56-64. Disponível em: http://www.scielo.br/pdf/reben/v65n1/08.p df.

9. Mello DF, Pancieri L, Wernet M, Andrade RD, Santos JS, Silva MAI. Vulnerabilidades na infância: experiências maternas no cuidado à saúde da criança. Rev Eletrônica Enf. [Internet]. 2014 [citado em 5 fev 2014]; 16(1):52-60. Disponível em: https://www.fen.ufg.br/revista/v16/n1/pdf/ v16n1a06.pdf.

10. Minayo MCS. O desafio do conhecimento: pesquisa qualitativa em saúde. 11ed. São Paulo: Hucitec; 2010.

11. Departamento Intersindical de Pesquisas e Estudos Socioeconômicos (DIEESE). Relatório analítico final da pesquisa socioeconômica em territórios de vulnerabilidade social no Distrito Federal. [Internet]. Brasília: DIEESE; 2011 [citado em 5 fev 2014]. Disponível em https://www.dieese.org.br/relatoriotecnico/ 2010/produto6.pdf.

12. Wright LM, Leahey M. Enfermeiras e famílias: um guia para avaliação e intervenção na família. 5ed. São Paulo: Roca; 2012.

13. Wrzus C, Hänel $M$, Wagner J, Neyer FJ. Social network changes and life events across the life span: a meta-analysis. Psychol Bull. 2013; 139(1):53-80.
14. Ayón C. Latino families and the public child welfare system: examining the role of social support networks. Child Youth Serv Rev. 2011; 33(10):2061-6.

15. McGoldrick M, Carter B, Petkov B. Becoming parents: the family with young children. In: McGoldrick M, Carter B, GarciaPreto $\mathrm{N}$, editors. The expanded family life cycle: individual, family, and social perspectives. 4th ed. Boston: Allyn \& Bacon; 2011. p. 211-31.

16. Osborne C, Berger LM, Magnuson K. Family structure transitions and changes in maternal resources and well-being. Demography. 2012; 49(1):23-47.

17. Tuney K. Perceived instrumental support and children's health across the early life course. Soc Sci Med. 2013; 95:34-42.

18. Cang J. Instrumental social support, material hardship, personal control and neglectful parenting. Child Youth Serv Rev. 2013; 35(9):1366-73.

19. Walker SP, Wachs TD, GranthamMcGregor S, Black M, Nelson CA, Huffman SL et al Inequality in early childhood: risk and protective factors for early child development. Lancet. 2011; 378(8):1325-38.

20. Byrnes H, Miller BA. The Relationship between neighborhood characteristics and effective parenting behaviors: the role of social support. J Fam Issues. 2012; 33(12):1658-87.

\section{CONTRIBUIÇÕES}

Aline Oliveira Silveira foi responsável pela concepção do estudo, elaborou o delineamento metodológico e contribuiu na análise, interpretação e discussão dos dados e na redação do artigo. Rafaella Costa Bernardes contribuiu na coleta, análise, discussão dos dados e da redação do artigo. Monika Wernet e Tatiana Barcelos Pontes contribuíram na redação e revisão crítica do artigo. Aline Araújo de Oliveira Silva colaborou na coleta e na análise dos dados. 